\title{
2
}

\section{The Latte Period in Marianas prehistory Who is interpreting it, why and how?}

\author{
Rosalind L. Hunter-Anderson \\ 1513 Wellesley Dr. NE, Albuquerque, New Mexico, USA
}

\section{Introduction}

'We know all about the Latte Period now so there is no need to dig anymore.'

Guam government official, 2006

Although most archaeologists familiar with Marianas prehistory would disagree with this statement, it indicates a widespread phenomenon in cultural-heritage matters, namely that many people tend to think about past cultures as composed of just a few essential elements. For some, Latte Period archaeology has already yielded all that is required.

This paper is about the various interpretations of Latte Period archaeological findings that one can find in the public arena today, and why and how they vary - even though they all refer to the 'same' prehistoric past. The paper is also about how people think about culture, particularly ancestral Chamorro culture, which is correlated with archaeological remains from the Latte Period. Variety in archaeological interpretation is apparent and inevitable in our pluralistic society: there are professional archaeological reports and publications, as well as newspaper, television and radio reports, video documentaries, internet blogs and websites, formal histories and textbooks. Cultural performances, celebrations and activities incorporating aspects of Chamorro heritage derived, in part, from Latte Period archaeology are also common both locally and on the internet.

These productions all share an interest in Marianas prehistory but they differ in their concepts of culture - from the very comprehensive to the minimal, or essentialist. Those that differ most from archaeological reports and publications, which tend to be comprehensive and detailed, hold an essentialist philosophical position regarding ancestral Chamorro culture. That is, they seem to assume that past cultures were unchangeable entities, each recognisable by a set of easily grasped defining elements. This tendency towards 'cultural essentialism' contrasts with a non-essentialist philosophical position and understanding of culture that is evident in much of the archaeological literature. Most archaeologists (although not all) think of culture as behaved, whether in the past or present, as a changeable, dynamic phenomenon, as adaptive systems that 
existed over time and space, invented by people and changed by them as needed.

As a dynamic system, a given culture cannot be reduced to a set of rigid, defining elements, like a list of ingredients on a cereal box (although some archaeological discussions include lists of culture traits that help identify the system under study and distinguish it from others). Philosophical differences over what a culture is, or was, lead to differences in goals and methods of involvement with the subject. To explain this idea further and to explore some of its implications, I have organised the paper as follows.

First, I introduce the concept of 'cultural essentialism' as it applies to current reconstructions and renditions of ancestral Chamorro culture, especially those invoking Latte Period archaeological data, and contrast this approach with that of most archaeologists working in this area. Next, I review some examples of popular treatments of ancestral Chamorro culture that reveal a cultural essentialist orientation, followed by some of my personal experiences in conveying archaeological findings in public venues. I conclude with some thoughts about how our communications with non-archaeologists can benefit from an awareness of pervasive cultural essentialism among the general public.

\section{Essentialism and cultural essentialism}

In philosophy, essentialism holds that for any specific kind of entity there is a set of characteristics or properties, all of which any entity of that kind must possess. The set of defining elements of the entity is permanent and unalterable; these elements are inherent in the entity. Plato may have been the first to formalise this idea. He asserted that there are two realities to the universe, the essential and the perceived, or what we might call the ideal versus the real (the one we experience every day). In the essential universe, everything is perfect and unchanging; there is no diversity. In the perceived universe, which Plato proposed was just a facade and by which we should not be fooled, diversity is rampant.

As you might expect, the founder of evolutionary theory, Charles Darwin, was not an essentialist. For Darwin, diversity not only affected the survival and reproductive prospects of the individuals in a population, it could be passed on to their offspring. Thus, a population could change, and given enough change, this evolutionary process would result in a new species. Anthropology and archaeology have similar notions regarding culture.

In our own lives as cultural beings, we usually do not operate under an explicitly essentialist position because we can easily see that our culture is complicated and always in flux. Our culture cannot be listed like the ingredients in a recipe. However, with respect to past cultures (and often cultures different from our own), many people seem to view them from an essentialist perspective: that far distant, or different, culture and its people are thereby reduced to a few easily recognised elements. A past culture becomes an ideal culture - frozen in a kind of timeless limbo not subject to outside influences.

\section{Constructing a past culture}

No one would dispute that ancestral Chamorro culture is no longer present as an entity to be experienced directly. Therefore, to give this concept meaning, one must (re)construct it. A strict essentialist approach would seek the set of defining elements untainted by outside influences. That Latte Period archaeology is a rich source of such untainted cultural evidence has not gone unnoticed by some of those interested in ancestral Chamorro cultural construction. For example, there are latte features, stone mortars, pottery bowls and jars, human burials in pits, human bone spears, Spondylus beads, sling stones, stone and shell adzes, marine-shell fishing 
gear, and volcanic-stone pounders and abraders, and much more, thanks to modern analytical techniques. For example, Latte Period archaeology provides descriptive evidence about foods, from microscopic and chemical analysis of organic residues on the interior surfaces of cookingpot fragments. Certain shellfish remains and bones discarded in domestic middens indicate which animal species were processed and consumed. Archaeology also has excluded certain elements from the picture, such as pig and dog. These domesticates do occur in prehistoric contexts in some other Pacific Islands, but not in the Marianas.

A less strict essentialist construction of ancestral Chamorro culture would admit alien elements, apparently if they have a long enough history of assimilation. The term 'antigo' applies here, as found in the 35th issue of the internet zine called Minaghet ('truth'). The author distinguishes between ancient, antigo and contemporary Chamorro culture (see http:// decolonizguam.blogspot.com/search?q=antigo). In Minaghet's usage, antigo refers to the olden times, after Spanish colonisation in 1668, well before modern times. Thus, for example, a lenient construction of ancestral Chamorro culture could include thatch-roofed huts on short wood posts, carabao, Sambar deer, Spanish dress styles and dances, the belembaotuyan (a single-string musical instrument), titiyas maies, (corn tortillas), older forms of Roman Catholicism, and Spanish-introduced items of material culture, such as the hotno (above-ground oven), fuziños (metal hoe) and metati (footed grinding stone).

What is remarkable to me, given the available information, is that relatively few of the total range elements are consistently invoked in contemporary discussions and depictions of ancestral Chamorro culture. Perhaps this reflects the operation of the process of reduction and simplification that has been noted among North American indigenous groups where there has been severe language loss, accompanied by loss or modifications of other traditions (Dauenhauer and Dauenhauer 1995). In this process, the ancestral culture is objectified and embodied by a core of essential elements that become fixed over time and ultimately become untouchable. For example, consider the case of the Tlingit of coastal Alaska. An audio tape collection of Tlingit stories told by elders in their preferred traditional manner, with clan affiliations and other introductory frames, recited by the tellers and considered integral to their storytelling tradition, was produced collaboratively by native-language-speaking linguists and Tlingit elders. The goal was to preserve the Tlingit language and culture. The recorded collection formed the basis for preparing culture-appropriate learning materials for tribal schools.

Two generations later, the collection resided in an archive that was off-limits to everyone by order of a tribal governing board whose members could not understand the stories that had been told in the manner considered right and proper by their elders. The board members insisted that simplified English 'translations' of these old stories should be used in the schools and the originals should remain locked up (as with holy relics). As Dauenhauer and Dauenhauer (1995) noted, in the process of heritage simplification, the ancestral stories so carefully preserved in that archive were reduced to a childish level, a format that also rendered them more acceptable to the surrounding dominant culture of English speakers.

A similar process seems to have been occurring with respect to depictions and invocations of ancestral Chamorro culture, and this is related to the severe heritage loss over the past 400 years amid the modern identity politics in an American-style political milieu found on Guam today. It certainly appears to have affected the way that archaeological findings are viewed by the public, including, and perhaps especially by, government officials. The belief that 'we know all about the Latte Period' may simply reflect the fact that, for essentialist purposes of ancestral culture construction, the few necessary elements provided by archaeology are well known and therefore need no further investigation. 


\section{Archaeology and a non-essentialist approach}

Professional archaeological approaches to culture actually vary along an essentialist-nonessentialist dimension, and some archaeologists do discuss past cultures in terms of trait lists. Yet many of us working in Micronesia tend to think about our findings in a non-essentialist framework. Instead of fixating on naming and classifying and arguing about definitions arguments such as, should a given artefact assemblage be called 'Lapita', 'Lapitoid' or something else - we non-essentialists have other interests and preoccupations. For instance, we assume that culture is a dynamic, changeable phenomenon and expect it to vary over time and across space. To many archaeologists, 'culture' is shorthand for 'cultural adaptive system' whose interrelated parts enable the system to persist over time and/or space by adjusting to and modifying (within limits) its social and physical environments. When these limits are exceeded cultural systems fail or evolve radically, so in this approach, the system is a 'moving target' for study.

In practice, non-essentialists seek patterns in archaeological and environmental data to help us imagine what past adaptive systems were like, how they were organised, how they functioned, and how and why they changed, if it appears that change and not just synchronous or cyclical variation has occurred. We are interested in the causes of system stability and instability, success and failure, over long and short time ranges and across small and large geographic areas. For example, Figure 1 is a graph of archaeological site types during the Latte Period (AD 900-1600) from the Manenggon Hills project in southern Guam, an area that encompasses about 1\% of the island's 549 sq km landmass (Hunter-Anderson 2008).

These data suggest that the ancestral Chamorro cultural system at this place was far from static. Through technical and social adjustments, people were responding to something, as indicated by the flux in site frequencies and especially the increase in the number and proportion of storage/camp sites. I propose that after AD 1300, ancestral Chamorros were experiencing highly variable harvests due to more frequent and longer droughts, and accordingly, they intensified planting and increased food storage. It appears that people responded to climatic

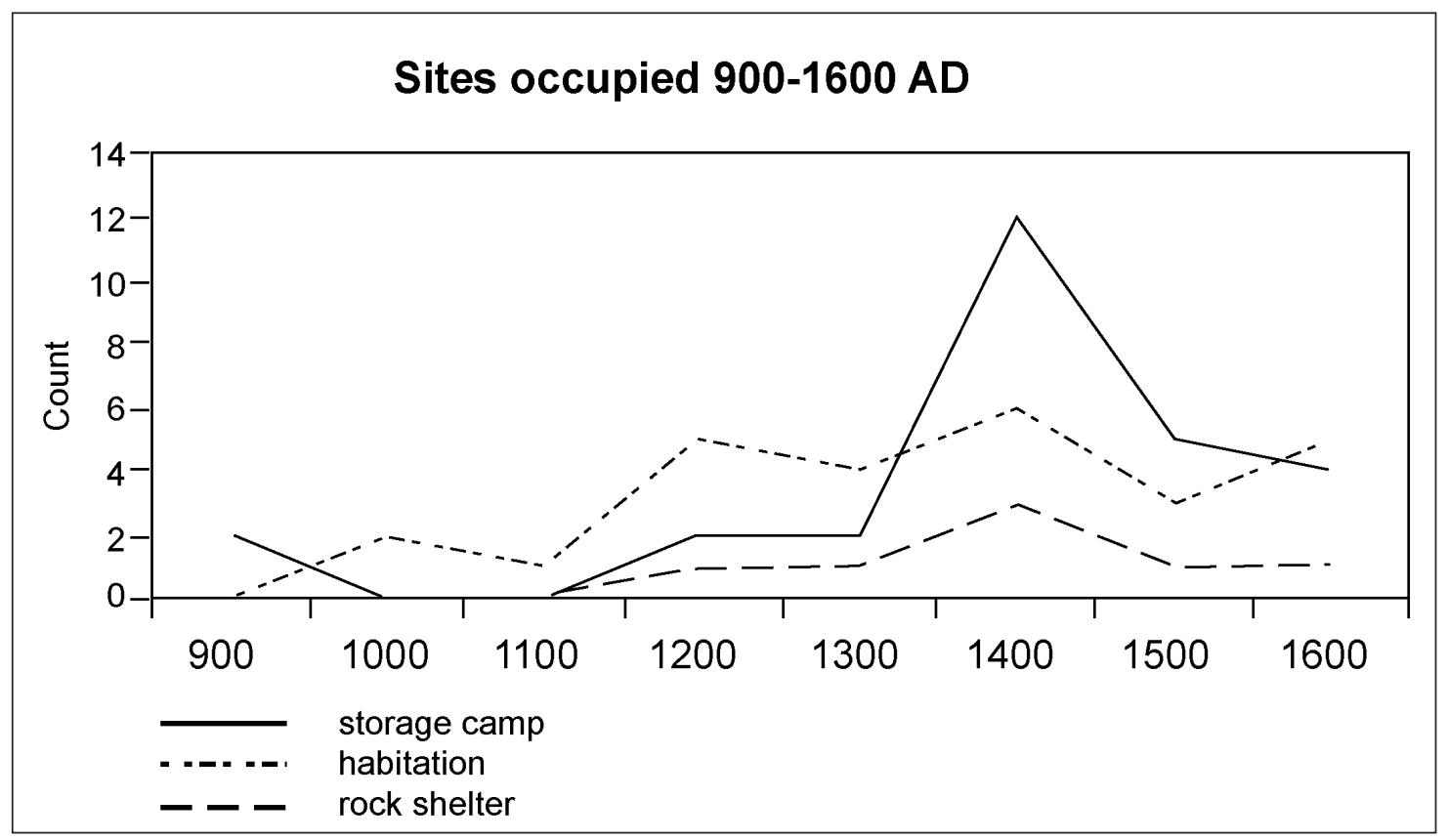

Figure 1. Frequencies of three types of site during the Latte Period at Manenggon Hills, Guam. Data from Hunter-Anderson (2008). 
change by doing more of what they already had been doing, namely, planting in the interior hills and using storage pits more intensively than they had previously. In ecology, this kind of behavioural response in a system experiencing environmental challenge has been called by van Valen (1973) the 'Red Queen Effect', after Alice's encounter with the Queen in Wonderland where increased effort in running was required to stay in the same place.

The non-essentialist archaeological approach is to explain the data, and the larger goal is to increase our knowledge of how cultural systems, including the dynamic ancestral Chamorro culture, acted under specific conditions. Data are generated by observation and are quantified to recognise significant patterns, for which a testable explanation is put forward.

Cultural essentialist goals and methods are different and less ambitious, at least as I have observed them. For example, the goals are limited to 1) preserving and protecting Chamorro culture, and 2) commanding respect for Chamorro culture. The methods used to further these goals include a) creating an attractive composite image of Chamorro culture by selecting elements known from archaeology and other sources, such as memory culture written down in the early 19th century and recorded in the early reports of foreign visitors, and b) transmitting this image in public venues. These efforts include museum and other static displays, paintings and drawings, wood and stone carvings, musical performances, recitation of poetry and chants, enactment of key events such as early encounters with foreigners and legends, and interpretations of archaeological features through websites, oral and written narratives and textbooks, and public protest demonstrations asserting proprietary control over archaeological materials and sites, especially human burials (see below), despite private property and historic preservation laws.

In 'multi-cultural' Guam, where ancient heritage loss is well documented and felt acutely by many, use of these methods by Chamorros whose ethnic identity is uncertain or ambiguous is strongly encouraged by those committed to the goals of preserving and protecting Chamorro culture and obtaining respect from outsiders. For example, a private $\mathrm{K}-12$ school incorporating elements of Chamorro culture in the academic curriculum was formed in 1994 by 'Chamorro activists' (Twaddle et al. 2003:35). Chamorro culture and language classes in the public schools were mandated by the Guam legislature in 1992 and there are regularly occurring events that remind people of the island's Chamorro heritage. During Chamorro Week and Chamorro Month, annual events on Guam, a range of cultural elements are displayed in various venues, including arts and crafts, language recitals and musical performances in 'period' dress. The yearly Micronesian Island Fair, usually held in a large public park in the tourist district of Tumon Bay, also offers an opportunity for the display of some essentials of Chamorro heritage (Figure 2). These displays in preserving cultural heritage are the subject of a thoughtful essay by Michael Lujan Bevacqua, who avers that culture is not static after all (see http://minagahet.blogspot. com/2009/11/decolonization-and-loincloth.html).

As Dauenhauer and Dauenhauer (1995) noted for the Tlingit and other groups experiencing cultural heritage loss, traditional foods are served during cultural celebrations. Guam's monthly fiestas that mark each village's saint's day in the Catholic religious calendar are no exception, involving Chamorro dishes not normally part of day-to-day life, which serve as potent symbols of a unique ancestry. Historic Preservation Week, sponsored by the Federal government through Guam's local historic preservation office, is another occasion when selected elements of ancestral Chamorro culture are invoked, such as sling stones, large stone mortars, latte architectural features, and plainware pottery from the Latte Period, displayed on posters and in exhibits in hotels and other public venues.

Most essentialist treatments of ancestral Chamorro culture ignore, or have no use for, temporal changes in archaeological data, such as we found at Manenggon Hills. This kind of 


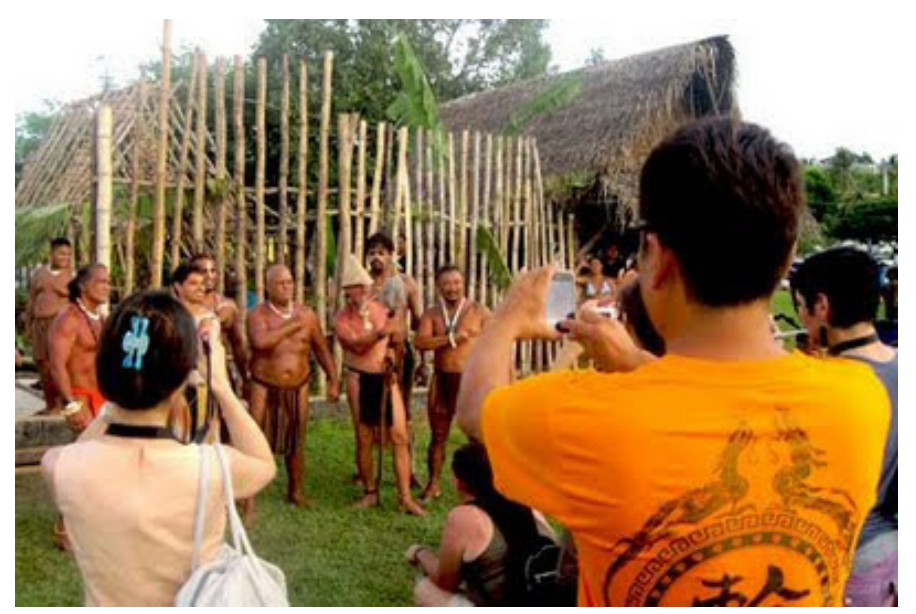

Figure 2. Photo of Guam Chamorros asserting cultural identity through costuming and constructing traditional architecture; from http:// minagahet.blogspot.com/2009/11/decolonization-and-loincloth.html

variability in cultural elements only confuses an essentialist picture of cultural continuity. Yet archaeologists immediately notice that certain elements are chosen for inclusion regardless of the time they were used or the systemic coherence that enabled these items and practices to exist. Consider, for instance, that the earliest archaeological evidence for human presence in the Marianas is consistently dated by radiocarbon assay no earlier than about 3500 years ago, give or take a couple of hundred years. This dating 'barrier' is not arbitrary and it is crucial for understanding the physical environment encountered by the first people to occupy the Marianas. Marine geological studies indicate that a high sea level before this time may have discouraged or even precluded successful landing and settlement (see Dickinson 2000, 2001). Figure 3 shows why mid-Holocene (pre-1500 BC) human occupation of the Marianas was unlikely. The high sea stand creates a high-energy sea-land interface, which, along with poor reef development, may have discouraged settlement.

While the existence of the Mariana archipelago may have been known to seafaring people of insular Southeast Asia, until environmental conditions improved, the Marianas remained uninhabited. After about 4000 years ago, sea level in the western Pacific began to decline from its mid-Holocene high stand. By around 3500 years ago, the sea had declined enough to allow the shores of the southern Mariana Islands to be approached by canoe and to serve as small camping platforms protected by reefs, which provided a rich source of marine foods.

These facts notwithstanding, and perhaps in the belief that earlier settlement is more admirable than the actual archaeological evidence for the timing of human advent in the Marianas, the human arrival date is often rounded up to 4000 years ago, or even more, on some popular websites and in text book discussions of ancestral Chamorro culture (e.g. Cunningham 1992:15; see also http://www.guam-online.com/history/history.htm; http:// www.pacificworlds.com/cnmi/arrival/ancients.cfm; http:/www.freewebs.com/allthingsguam/ virtualhistorytextbook.htm).

Assertions of a great antiquity for human occupation of the Marianas ignore the significance of the sea-level barrier before ca. $1500 \mathrm{BC}$, while also missing the significant fact that the earliest people to leave archaeological evidence of their presence precede by at least 500 years human advent in the other remote Oceanic islands of the Pacific - as Craib (1999) noted more than a decade ago. We do not yet have an explanation for this anomaly, and few researchers have considered the issue (e.g. Hunter-Anderson 2005:30-31, 2008). 


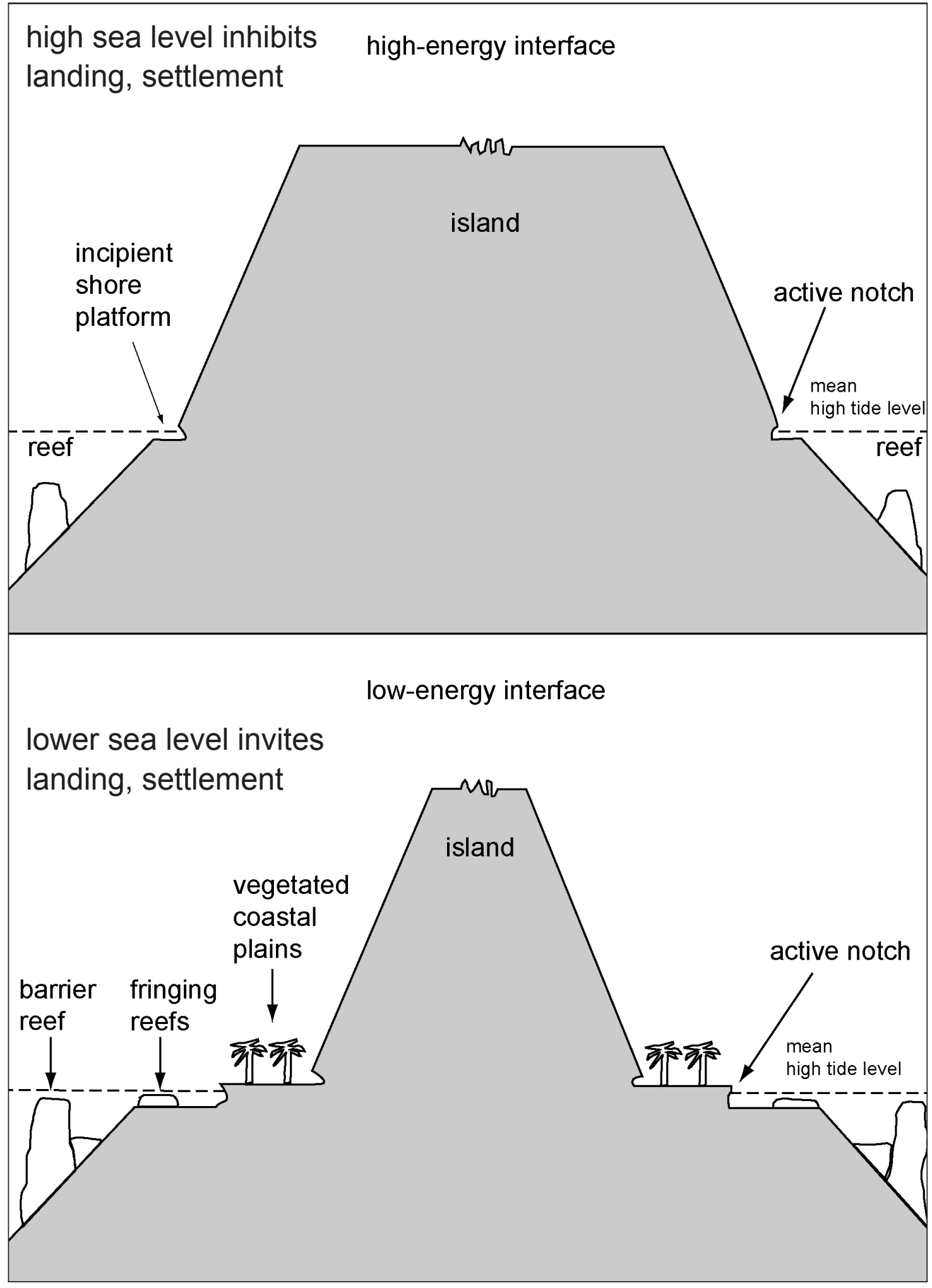

Figure 3. Mid-Holocene sea level and high-energy sea-land interface; late-Holocene sea level and low-energy sea-land interface. Modified from Nunn (1994). 
Another questionable element in popular treatments of ancestral Chamorro culture is the assumption that the first people to arrive in the Marianas were fisher-farmers who pursued a way of life identical to that described in early historic accounts and from memory culture collected in the 19th century, despite the fact that the earliest Marianas cultural deposits, called Early PreLatte by archaeologists, contain no agricultural tools, nor any signs of a settled way of life, such as dense middens, substantial residential and other structures, or even human burials. While these anomalous absences are fascinating to archaeologists working in these islands, they tend to be ignored by cultural essentialists as they seek to connect the deep past of the Marianas with ancestral Chamorro culture.

\section{Ancestral Chamorro culture in the local mass media}

How do newspaper and television reports of Latte Period archaeology fit into an essentialist/nonessentialist distinction? Almost by definition, journalistic accounts are essentialist in that they must clearly inform us about essentials: what, where, who, when and how. The most common reason for local archaeological stories to appear in the local mass media is the accidental exposure of prehistoric human remains during construction projects, especially when historic preservation laws appear to have been violated. During reportage of 'what', the skeletal remains and any associated artefacts are automatically identified as ancestral Chamorros, usually on the advice of archaeologists. Photographs may be included in the piece, and they tend to be of recognisable objects such as stone and shell tools and human skulls. A skull and artefacts displayed on a local television station came from what archaeologists call Late or Transitional Pre-Latte cultural deposits and probably date between 2500 years ago and 2000 years ago (DeFant and Eakin 2009). If they are not re-interred, some day they could figure in public exhibitions and posters as elements of ancestral Chamorro culture, despite being made of stone exotic to the Marianas and having been found buried with individuals whose morphology is quite different from that of Latte Period burial populations.

Other journalism involving Latte Period archaeology includes reporting on protest demonstrations, such as events in which an activist group publicly objects to an archaeological mitigation project. In Guam, activists have characterised archaeological work on prehistoric materials as a desecration of ancestral Chamorro heritage (see entries at http://decolonizeguam. blogspot.com/2007/08/desecration-of-chamorro-remains-at.html). In such cases, the reporter focuses on the 'controversy' between local historic preservation laws and the activists' assertions of proprietary control of the remains, with the archaeologists caught in the middle and usually blamed for insensitivity or worse. Local laws mandate that the archaeological work be conducted on behalf of landowners or developers and paid for by them. Re-interment of human remains after minimal analysis is also required, and such ceremonies are reported in the local mass media, although there is usually only a small public attendance at these events.

A cultural essentialist position is generally adopted by activists and government officials in such cases. All human burials of early and late prehistoric age are considered essential elements of ancestral Chamorro heritage, and now have been accorded a near-sacred status similar to that of the Tlingit stories archive. Archaeologists familiar with the prehistoric record of human interments in the Marianas would know that secondary burials that often lack the skull and/ or long bones testify to different funerary treatment accorded to many remains during the late prehistory of the Latte Period.

Journalistic alternatives to the quick report about the accidental finding of Latte Period remains include longer pieces in magazines, in video documentaries and on internet websites. 
When based on adequate research, they serve as reliable references and ultimately reach a large audience composed of people more interested in the subject than the average newspaper reader or television viewer. Perhaps not surprisingly, however, a cultural essentialist view permeates many of these products. For example, the Guampedia (http://guampedia.com/) organises the Ancient Chamorro Era in an outline-list of separate cultural topics. From the topical presentation style, one might conclude that ancestral Chamorro culture consisted of separate, free-standing parts: a list of ingredients without the cooking instructions.

Formal histories offer longer and more reflective discussions. Russell's (1998) Ancient Chamorro culture and history of the Northern Mariana Islands and Rogers' (1995) Destiny's landfall elaborate on the various aspects of prehistoric occupation of the Marianas. In his archaeological summaries, Russell speculates on human motives for initial settlement and reviews several theories regarding variations and trends within the Latte Period; after all, the author is a historian. Rogers also recognises major archaeological changes in Marianas prehistory and proffers an explanation for the rise and persistence of Latte Period society, privileging population growth and resulting competition for limited resources. Both authors' interpretations reflect consultations with local archaeologists, and perhaps because of this come closest to a non-essentialist position regarding past cultures and their histories than do the views in popular literature.

From this brief overview, it seems archaeologists have their work cut out for them if they want to influence public thinking about past cultures. Cognitive scientists and linguists have found that new information is best assimilated in narrative form (Herman 2003). I suspect we need to work on our storytelling.

\section{Experiences in conveying archaeological information to the public}

Over the nearly 30 years that I have lived and worked in the Marianas and neighbouring islands, I have had the pleasure and challenge of trying various methods to convey archaeological findings to non-specialists. In addition to teaching university undergraduates and briefly hosting school children visiting archaeological sites where I was working, these efforts include producing a public radio series called Island Archaeology: Reports from the field, which later morphed into a live weekly broadcast called Island Archaeology; writing a chapter on Guam's prehistory for a textbook called Guam history: Perspectives volume 2 (Carter et al. 2005); and most recently presenting a paper at a symposium called The human dimensions of climate change at the annual meeting of the Society for Human Ecology in Bellingham, Washington (Hunter-Anderson 2008). I will briefly describe these efforts and various reactions to them.

At the Society for Human Ecology symposium on climate change I was the only archaeologist presenting a paper and apparently the only one in the entire meeting. The climate-change session organiser was an environmental philosopher, Thom Heyd (University of Victoria, Canada), who had invited several of his colleagues as well as land management specialists and urban planners. Everybody in the presenting group and most of the audience was very concerned about the coming climate Armageddon due to global warming, but showed little or no awareness of longterm climate trends. For my presentation, I used some of the Manenggon Hills project data to remind people that such trends are known and to argue that a prehistoric cultural system had successfully coped with century-scale climate change towards more severe droughts in the western Pacific during the Little Ice Age. I proposed that the ancestral Chamorro coping mechanisms were both technical and social. After the session, people told me they had enjoyed my paper and some asked for copies, but I felt I had failed to accomplish my goal to quicken their interest in past climate oscillations and encourage them to consider the possibility that 
today we might be in just another one. Thus, my effort was evidently a diversion into another culture and era, but not a point of departure for thinking differently about human ecology as the study of human-environment relationships over long time scales.

Subsequently, I was asked by the session organiser to step down as a co-editor of the published papers. Here is part of his letter to me explaining why:

... I appreciate your help with the special issue so far. Now, I did think about our completely opposite ways of thinking of our climate change situation, and I obviously made a mistaken assumption: that you would be of the same mind on anthropogenic climate change as I am. My mistake, obviously.

Under these circumstances I do think that it would be better to have someone else as co-editor, since part of the task may be to think through how the urgency of the situation can be transmitted. In fact, I did ask a friend who has been working on that angle with me before and he says that he is very ready to take this on. I hope that you do not take this change personally.

I do not take it personally, but I do take it professionally. I have concluded from this polite exchange that the long interaction between people and the environment that archaeologists take for granted is quite alien to others and evidently holds few lessons for contemporary problems. We have some work to do to change that.

Another venue in which I have participated in conveying archaeological information is a local history textbook Guam history: Perspectives volume 2 published by the Micronesian Area Research Center at the University of Guam. My 39-page chapter in this work was an informal, unfootnoted overview of Guam's prehistoric record. Naturally, my perspective is anthropological, and the discussion covers several aspects of the 3000-year-long span of prehistoric human presence in the island as a part of the Mariana archipelago and tropical western Pacific region. I believe it is the only textbook presentation on Marianas prehistory by an archaeologist designed expressly for secondary school students and the lay public. As for reactions to this piece, I am not aware of any. The first volume in the Guam perspectives series (Carter et al. 1997) can be purchased from Amazon.com and other internet bookstore sites, but volume 2 is nowhere to be found in the Guam public schools, cyberspace or local bookstores. Internet searches have revealed no reviews of the book, and according to Google Scholar, my chapter has not been cited in any article or book, and only one other contribution (Gracy 2005), about the late governor of Guam, Bill Daniels, has been noted on the internet (see http://www.ischool.utexas.edu/ - gracy/ research.html). I wonder whether all the effort expended by the editors, authors and production staff to produce a textbook was justified.

Another outreach project was the radio program called Island archaeology: Reports from the field, which I produced in the 1990s under a grant from National Public Radio (NPR) in collaboration with staff at Guam's new public radio station (KPRG). Making the series was fun, even though it required a lot of preparation and coordination of people and equipment. The sound man from KPRG and I visited archaeological projects as they were happening, as well as visiting the local archaeological laboratories of a contract firm where archaeological findings were being analysed. Some episodes were structured studio interviews that covered topics like prehistoric pottery and what can be learned from its detailed study; palaeoenvironmental investigations such as pollen analysis of ancient wetland sediments; and why people go into archaeology. We made 11 episodes, each about 10 minutes long, and the series got plenty of local play. Unfortunately, the recording quality was not up to NPR standards, and we had to abandon our plans to provide the series on Marianas archaeology for national airplay. Local listeners appeared to enjoy the program, and one even sent the station $\$ 100$ to support the program. 
A few years later, Richard Olmo and I co-hosted a similar program on KPRG. This one did not involve field recordings; rather, each episode was recorded in studio and ran about half an hour. The programs were conversations between the two of us about local archaeological projects and their implications. At first, we recorded each segment ahead of time, and later we did most of them live. The program came on during the lunch hour. Having been in graduate school in the 1970s, naturally our theme song was from the film Raiders of the Lost Ark. Occasionally, the station got telephone calls from listeners commenting that they enjoyed the program, but public interaction was quite limited. I believe these programs are still played occasionally.

One of the grant requirements for doing Reports from the field was to have the series evaluated by listeners. This was not practical to do over the radio, but fortunately, Professor Vince Diaz, then at the University of Guam, assisted with a student evaluation. For extra credit in his history of Guam class in 1996, students could listen to the tapes in their own time and answer questions about them. The listening environment was, of course, different: the 11 students who responded had to sit still and listen to the tapes one after another, rather than hearing the separate programs on the radio over a period of several weeks. The classroom setting is very different from how people usually listen to programs on the radio. However, in their overall evaluation of the program, most of the students said they enjoyed the series and learned new things. Many wished the episodes were longer, to include more information and clarification about specific points of interest. All remarked that making the series on video would have been better than simple audio recordings.

Below are a few quotes from the questionnaire. All the students were non-anthropology majors, and their ethnic backgrounds include Chamorro, Filipino and Chinese. Many were studying to become elementary or secondary-school teachers.

'I really enjoyed listening to the tapes. It was really interesting. I guess hearing things about our history or watching it on video has a better effect on people.'

'Dr. Diaz, I really didn't like this program. I found it to be very boring but of course educational. I'm not really interested in archaeology ...'

'Overall I thought the program was interesting and I learned a lot about what archaeologists do and how they can tell of our past from pieces of artifacts they find.'

'Everyone has a right to learn about the past because everyone [is] a product of the past.'

'Whenever I hear the word "archaeology" I usually think of American scientists, but after hearing this episode, it really amazed me that there are Micronesian archaeologists out there.'

'The least interesting information to me was when some of the scientists talked too long on a certain subject that didn't need a lot of explanation, and also some of the information bored me. But overall the program was good and interesting. I learned a few things from the program.'

And my favourite:

'Make it a little more lively. The woman talking makes me want to fall asleep.'

\section{Final thoughts}

I have suggested that it is important archaeologists realise most people outside our field are 'cultural essentialists' and the latter realise that archaeologists do not share this view. This could explain why effective communication of our research seems so elusive. There will always be resistance to dissonant facts because they disrupt our previous conceptions; scientists have this 
problem, as does the general public. But I suspect we can broaden not a few minds if we produce compelling and accurate stories about our work and its meanings. Guam youth evidently prefers visual learning, but then many adults I know do as well.

Another communication issue is our credibility as professionals; this is surely important in this democratic age of self-proclaimed experts. More critical is that the information we try to convey stands on its own merits. In short, the messenger is not the message, the message is. Avoiding argument from authority and jargon that creates distance and distrust impels us to clarify what needs explaining and why: our stories must reflect the reasoning and data supporting our interpretations, and an honest airing of known problems with the data is also important. Some do this better than others, and judging from my own experiences, there is room for improvement among all of us. 


\section{References}

Bak, P. 1996. How nature works, The science of self-organized criticality. Springer-Verlag, New York.

Carter, L.D., Wuerch W.L. and Carter R.R. (eds), 1997. Guam history: Perspectives volume 1 MARC Educational Series No. 20. Richard F. Taitano Micronesian Area Research Center, University of Guam.

Carter, L.D., Wuerch, W.L. and Carter R.R. (eds), 2005. Guam history: Perspectives volume 2. MARC Educational Series No. 23. Richard F. Taitano Micronesian Area Research Center, University of Guam.

Craib, J. 1999. Colonisation of Mariana Islands: New evidence and implications for human movements in the Western Pacific. In: Galipaud, J.-C. and Lilley, I. (eds), The Pacific from 5000 to 2000 BP, Colonisation and transformations, pp. 477-485. IRD Editions, Paris.

Cunningham, L. 1992. Ancient Chamorro society. Bess Press, Honolulu.

Dauenhauer, R. and Dauenhauer, N.M. 1995. Oral literature embodied and disembodied. In: Quasthoff, U.M. (ed), Aspects of oral communication, pp. 91-111. Walter de Gruyter, New York.

DeFant, D. and Eakin, J. 2009. Preliminary findings from the Naton Beach site, Guam. Paper presented at the Pacific Island archaeology in the 21st century conference, Koror, Republic of Palau, July $1-3$.

Dickinson, W.R. 2000. Hydro-isostatic and tectonic influences on emergent Holocene paleoshorelines in the Mariana Islands, western Pacific Ocean. Journal of Coastal Research 19:735-746.

Dickinson, W.R. 2001. Paleoshoreline record of relative Holocene sea levels on Pacific islands. EarthScience Reviews 55:191-234.

Gracy, D.B. II. 2005. To build Rome in the morning: Bill Daniel's first days as governor of Guam, 1961. In: Carter, L.D., Wuerch, W.L. and Carter, R.R. (eds), Guam history: Perspectives volume 2, pp. 283-337. MARC Educational Series 27, University of Guam, Mangilao.

Herman, D. (ed), 2003. Narrative theory and the cognitive sciences. University of Chicago Press, Chicago.

Hunter-Anderson, R.L. 2005. An anthropological perspective on Marianas prehistory, including Guam. In: Carter, L.D., Wuerch, W.L. and Carter, R.R. (eds), Guam history: Perspectives volume 2, pp. 20-59. MARC Educational Series 27, University of Guam, Mangilao.

Hunter-Anderson, R.L. 2008. Cultural responses to late Holocene climatic oscillations in the tropical western Pacific: A new interpretation of the prehistoric Latte Period of Guam, Mariana Islands, Micronesia. Paper presented at the XVI International Conference of the Society for Human Ecology, Bellingham, Washington, September 10-13.

Nunn, P.D. 1994. Oceanic Islands. Blackwell Publishers, Oxford.

Rogers, R.F. 1995. Destiny's landfall: A history of Guam. University of Hawai'i Press, Honolulu.

Russell, S. 1998. Ancient Chamorro culture and history of the Northern Mariana Islands. Micronesian Archaeological Survey Report No. 32, Saipan.

Twaddle, I., Roberto, J.P. and Quitanilla, L.D. 2003. Chamorro perspectives on mental health issues in Guam: Cross-currents of indigenous and western cultural discourses. South Pacific Journal of Psychology 14:30-59.

van Valen, L. 1973. A new evolutionary law. Evolutionary Theory 1:1-30.

\section{Websites}

http://decolonizeguam.blogspot.com/search?q=antigo

http://www.gdoe.net/chamstud/

http://www.guam-online.com/history/history.htm

http://www.pacificworlds.com/cnmi/arrival/ancients.cfm

http://www.freewebs.com/allthingsguam/virtualhistorytextbook.htm

http://decolonizeguam.blogspot.com/2007/08/desecration-of-chamorro-remains-at.html

http://guampedia.com/

http://www.ischool.utexas.edu/ gracy/research.html

http://minagahet.blogspot.com/2009/11/decolonization-and-loincloth.html 